\title{
Potential of Aqueous Extracts from Parts of the Pepper Tree (Schinus molle L.) to Affect Emergence and Seedling Development of Wheat (Triticum sativa $L_{\text {. }}$ ) and Weeds in a Manure Amended Soil
}

\author{
Simeon A. Materechera* and Malipholo E. Hae \\ Crop Science Programme, Faculty of Agriculture, Science and Technology, North-West University (Mafikeng Campus), \\ P/B X2046, Mmabatho 2735, South Africa
}

\begin{abstract}
The allelopathic potential of aqueous extracts from fruits, leaves, roots and bark of the pepper tree (Schinus molle L.) were investigated on emergence and seedling development of wheat (Triticum sativa L.) and agricultural weeds. Different concentrations of the original extract (undiluted, 1:1, 1:3 and water, v/v) were applied to a soil amended with cattle manure in 2-litre pots. Extracts from all the tree parts significantly $(p<0.05)$ reduced seedling emergence, height and dry matter yields of wheat and weed seedlings compared to the control (water). The inhibitory effects on both wheat and weed seedlings were consistently in the order fruit=leaves >roots $>$ bark. The inhibitory effects were however progressively reduced by diluting the original extracts suggesting that there was reduction in the concentration of the compounds inhibiting the emergence and development of seedlings.

The weed population and species composition were negatively affected by tree extracts but improved with dilution of the extracts. It was observed that grass weed species were relatively more adversely affected by the inhibitory compounds in the extracts than broad leaf species at each level of extract dilution. The results confirm the presence of water-soluble compounds in the tissues of the pepper tree which can inhibit seedling emergence and growth of wheat and weed seedlings. It is concluded that the pepper tree posses allelopathic characteristics that may be explored for weed management in agriculture. Further investigations are recommended to elucidate the nature of the phytotoxin, formulation, mode of application and the appropriate economic way of exploiting this potential.
\end{abstract}

Keywords: Phytotoxin, aqueous extracts, inhibitory compounds, weed control, manure, Schinus molle.

\section{INTRODUCTION}

Worldwide, weeds and weed control have become a major cost factor determining the economic profitability of crop production [1]. Weeds compete with crops for light, nutrients and moisture, resulting in losses of grain yield and quality. Furthermore, weed control is costly as it demands the use of labour and chemicals both of which are usually less affordable resources for most small-scale farmers in developing countries.

Allelopathy is defined as a mechanism by which plants, directly or indirectly affects, inhibits or stimulates, growth of others by the production of chemical compounds (phytotoxin) released to the environment [2]. The use of allelopathy for weed management has received strong attention in recent times [3-7]. This is because phytotoxins are considered to be more environmental friendly as opposed to synthetic chemicals of which some have been shown to contaminate water and soil resources thereby constituting risk to human and animal health [8]. Consequently, the use of natural substances from plants is seen as a low input and sustainable approach to integrated weed management [9-11]

*Address correspondence to this author at the Crop Science Programme, Faculty of Agriculture, Science and Technology, North-West University (Mafikeng Campus), Mmabatho 2735, South Africa; Tel: +27 183840 806; Fax:+27 183862 686; E-mail: albert.materechera@nwu.ac.za which can also help to reduce the rising incidences of herbicide resistance in weeds $[12,13]$.

Studies have shown the inhibitory effects of plant species on not only weeds $[6,14,15]$, but also on growth and yields of crop species [16-18]. The allelopathic and herbicidal effectiveness of different plant species has been shown to depend on the plant part [2]. There is therefore need for exploration of plants and parts with effective allelopathic activity, especially in the control of agricultural weeds. In South Africa, this may be more cost effective for small-scale and emergent farmers who have limited financial resources to afford the cost of labour and herbicides to control weeds [19].

Pepper tree (Schinus molle L. Anacardiaceae), is an evergreen, fast growing, heat and drought resistant ornamental tree species. It originates from South America and has been naturalized and extensively planted along main roads and residential homesteads in South Africa. Although the pepper tree is valued for the shade it creates, it has been classified as one of the invasive garden plant species that is considered to have a substantial impact on natural and seminatural ecosystems [20]. The pepper tree, with its weeping branches, feathery pinnate leaves, grows to a height of 4 to $10 \mathrm{~m}$ and produces clusters of attractive pink to reddish berry-like fruits. Phytochemical analyses have shown that the pepper tree contains aromatic compounds in the form of tannins, alkaloids, flavonoids, steroidal saponnins and large 
amounts of essential oil, some of which could have allelopathic effects [21].

A common observation associated with the growth of the pepper tree has been the presence of bare soil patches around the areas where the tree is growing and also the presence of selected weed species compared to areas further away from the tree canopy. It is however not clear whether the inhibition of vegetative growth around the tree is due to exudates from the plant's above or below ground parts, shading or competition for growth resources. Although the potency and phytotoxic effects of extracts and essential oils from the pepper tree have been shown to have pesticidal and antimicrobial properties [21-23], there has been no study done to explore this potential for weed management in crop production systems. On the other hand, the protection of crops from weeds and other vegetation that inhibits crop growth is a constantly recurring problem in agriculture. This problem calls for the need to exploit the potential of allelopathy to enhance weed control in crop production [3].

The aim of this study was to evaluate the allelopathic effects of aqueous extracts from parts of the pepper tree on emergence and growth of wheat (Triticum aestivum L.) and weed seedlings. The efficacy of the extracts on the population and species diversity of common agricultural weeds was also studied.

\section{MATERIALS AND METHODS}

\section{Collection of Tree Parts}

Fresh fruits, leaves, bark and roots of pepper trees growing within a $5 \mathrm{~km}$ radius of the North-West University (Mafikeng campus) were sampled in April 2006. All parts were washed with distilled water and dried in an oven at $60^{\circ} \mathrm{C}$ for $72 \mathrm{~h}$. The dried material was chopped into small pieces (1-2 cm size) using a mechanical chopper (Model MF 10 IKA WERKE, South Africa) and then ground into powder using a plant tissue grinder (Model TECA TORCEMOTEC 1090, South Africa) with a $2 \mathrm{~mm}$ sieve. The dry powders were stored in glass bottles and kept at room temperature until extraction.

\section{Preparation of Aqueous Extracts}

The original extract was prepared by mixing $100 \mathrm{~g}$ of the dried plant part powder to $100 \mathrm{ml}$ of deionised water. This ratio was used on all plant parts. Aqueous extracts were made using the method of [18]. Different concentrations $(1: 1,1: 3$ and water $\mathrm{v} / \mathrm{v})$ of the original undiluted extract were prepared by mixing the original extract with deionised water. The solutions were kept in a refrigerator at $5^{\circ} \mathrm{C}$ until bioassay.

\section{Experimental Design and Layout}

Treatments consisted of a combination of two factors viz: four tree parts (leaves, fruits, bark and roots) and four dilutions (undiluted, 1:1, 1:3; and water $\mathrm{v} / \mathrm{v}$ ) of each part. The water treatment served as a control. The experimental design was a randomized complete block with four replicates. PVC pots with a volume of two litres were filled with air-dried soil collected from a maize field at the University farm. The soil was from the sub-surface $(20-40 \mathrm{~cm})$ of a red sandy loam, classified as Hutton form according to the South African soil classification system [24]. Preliminary tests indicated that the soil at this depth was devoid of weeds. The soil in each pot was thoroughly mixed with airdry, partly decomposed cattle manure (1:3 v/v parts; manure: soil) collected from the floor of the dairy kraal at the University farm in order to increase the weed seed bank in the soil [25]. The pots were placed in a glasshouse where the day and night temperatures were $27 \pm 3{ }^{\circ} \mathrm{C}$ and $15 \pm 2{ }^{\circ} \mathrm{C}$ respectively. The experiment was repeated after three weeks and the results have been combined as replicates.

\section{Wheat and Weed Growth Bioassay}

Wheat (Triticum sativa L. cv SST 825) was used for the bioassay due to its sensitivity to agrochemicals. Ten seeds were sown in each pot at a depth of $10 \mathrm{~mm}$. From planting time, each pot was watered to field capacity with the appropriate aqueous extract solution at two-day intervals. The plants were grown for a period of 4 weeks after emergence when the weed species could easily be identified. Seedling emergence percentage of wheat was calculated by dividing the total number of seedlings that emerged by the total seeds sown in each pot. For both wheat and weeds, emergence was considered to be when the shoot of the seedling had protruded to at least $1-2 \mathrm{~mm}$ above the soil. At the end of the growing period, roots of both wheat and weed species were washed free of soil by running a stream of tap water over a $1.0 \mathrm{~mm}$ sieve to remove the adhering soil particles.

Plant height and root length of wheat seedlings were measured with a ruler. Fresh and dry matter yields of the shoots and roots in each pot were measured respectively by weighing the materials before and after drying in an oven at $65^{\circ} \mathrm{C}$ for $48 \mathrm{~h}$. The numbers of weed seedlings that had emerged in each pot were counted and the species were identified and classified as either broadleaf or grass using the keys provided by [26] and [27]. After identification, all the weeds from each pot were placed in paper envelopes and dried in the oven at $60^{\circ} \mathrm{C}$ for $48 \mathrm{~h}$ to determine dry matter.

\section{Statistical Analysis}

All the data were subjected to analysis of variance (ANOVA) using the General Linear Model procedure of the Statistical Analysis System [28]. The emergence percentages were transformed to angular values using an arc-sine function in order to normalize them and analysis of variance was conducted on the transformed data [29]. The Duncan's Multiple Range test was used to separate the means where significance was indicated.

\section{RESULTS AND DISCUSSION}

The analysis of variance showed significant interactions $(P<0.05)$ between tree parts and extract concentrations (dilutions) on all the measured parameters in both wheat and weeds. All the growth parameters measured in wheat were significantly reduced $(P<0.05)$ by undiluted extracts of tree parts (Fig. 1). The reductions were less when the original undiluted extracts were diluted with water. All the measured parameters improved progressively with each level of dilution. Within the dilution treatments, the inhibitory effects of the tree parts on growth of wheat were consistently in the order fruits $=$ leaves $>$ roots $>$ bark suggesting differences in concentration of phytotoxin in the parts of the tree. The effects of the bark were significantly lowest $(P<0.05)$ 

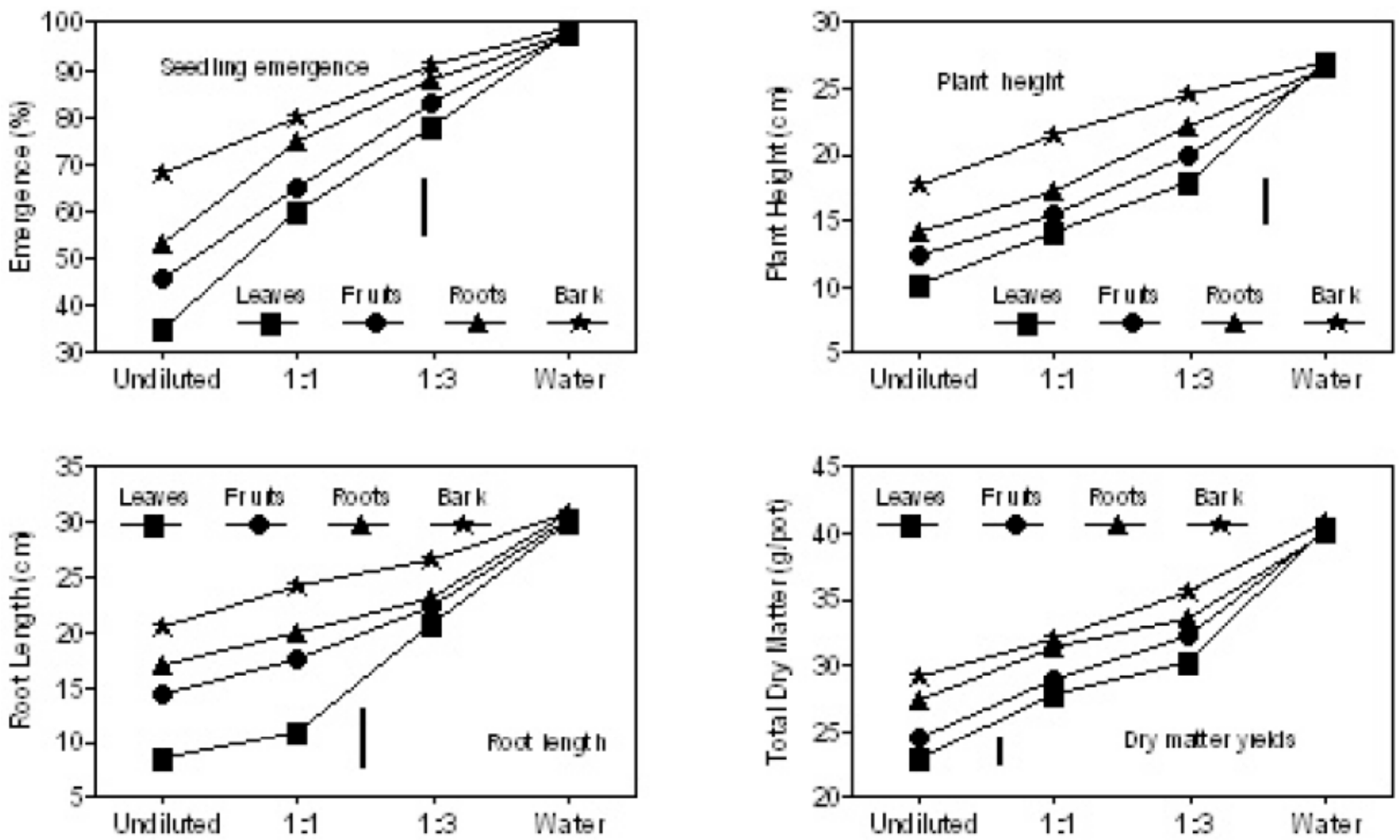

Fig. (1). The interactive effects of tree parts and their dilutions on growth of wheat seedlings. The bar represents the least significant range at the 0.05 probability level according to the Duncan's Multiple Range Test.

compared to the other parts. Differences among the latter were more evident in the undiluted extract and became less with dilution. Generally, seedling emergence was the parameter most affected by the extracts followed by plant height, root length and total dry matter (Fig. 2).

When the non-emergent wheat seeds were excavated and examined, it was observed that the majority did not germinate or had only partly germinated suggesting that the inhibitory compounds in the extracts may have affected the germination process [8]. This is consistent with the suggestion of [3] who indicated that the enzymatic processes involved in seed germination are more sensitive to potency of extracts than seedling development. According to [3] and [8], disruption of some processes can result in complete suppression of seed germination. This could explain the existence of bare patches observed under the canopy of most pepper trees which could be related to the failure of seeds of plants, especially weeds, to germinate in this soil environment.

The populations of both weed and species were significantly reduced $(P<0.05)$ by the extracts from different tree parts (Fig. 3). As was the case with wheat seedlings, the bark had the least effects compared with fruits, leaves and roots in reducing the population of weeds and species. Fruits and leaves had the most severe inhibition at each level of extract concentration (dilution). In all the tree parts, the reductions were highest in the undiluted extracts and progressively increased with dilution. There was a higher occurrence of grass weed species numbers compared with broadleaf among all the tree parts. However, the effects of both tree parts extracts and their dilution showed a similar pattern in both weed and species population. Except for the water treatment, the weed populations and species diversity were significantly higher $(P<0.05)$ in the bark and roots compared to those in the extracts from leaves and fruits at all other dilutions. The results for weed dry matter followed a similar trend. Total weed population was the parameter most adversely affected by the extracts while dry matter was the least.

Out of the ten weed species that emerged in the study, $60 \%$ were grass while $40 \%$ were broadleaf (Table 1). The majority $(90 \%)$ of the weed species were classified as annual weeds. The occurrence of large numbers of annual grass weed species could partly be a reflection of the dominance of such species in the veld (grazing lands) where most of the cattle are grazed in this semi-arid environment [30]. The dominant grass weed flora that occurred were Cynodon dactylon, Dactyloctenium austral and Sporobolus nitens while for broadleaf it was Chenopodium album and Tagetes minuta. The trend in the occurrence of both grass and broadleaved weed species were similar in that both were higher in the extracts from bark and roots than leaves and fruits. The numbers of weed species were largest in the control and progressively reduced by increasing the dilution of the original extracts. The total weed occurrence was reduced by $64 \%$ (undiluted), $51 \%(1: 1)$ and $29 \%(1: 3)$ in the $1: 3$ dilutions (Fig. 4). This implies a stronger efficacy of the extracts in the former. At each level of dilution, the reductions were higher in grass than broadleaf weeds. In all the species categories (annual or perennial), the control had the highest number of both grass and broadleaf species. The 

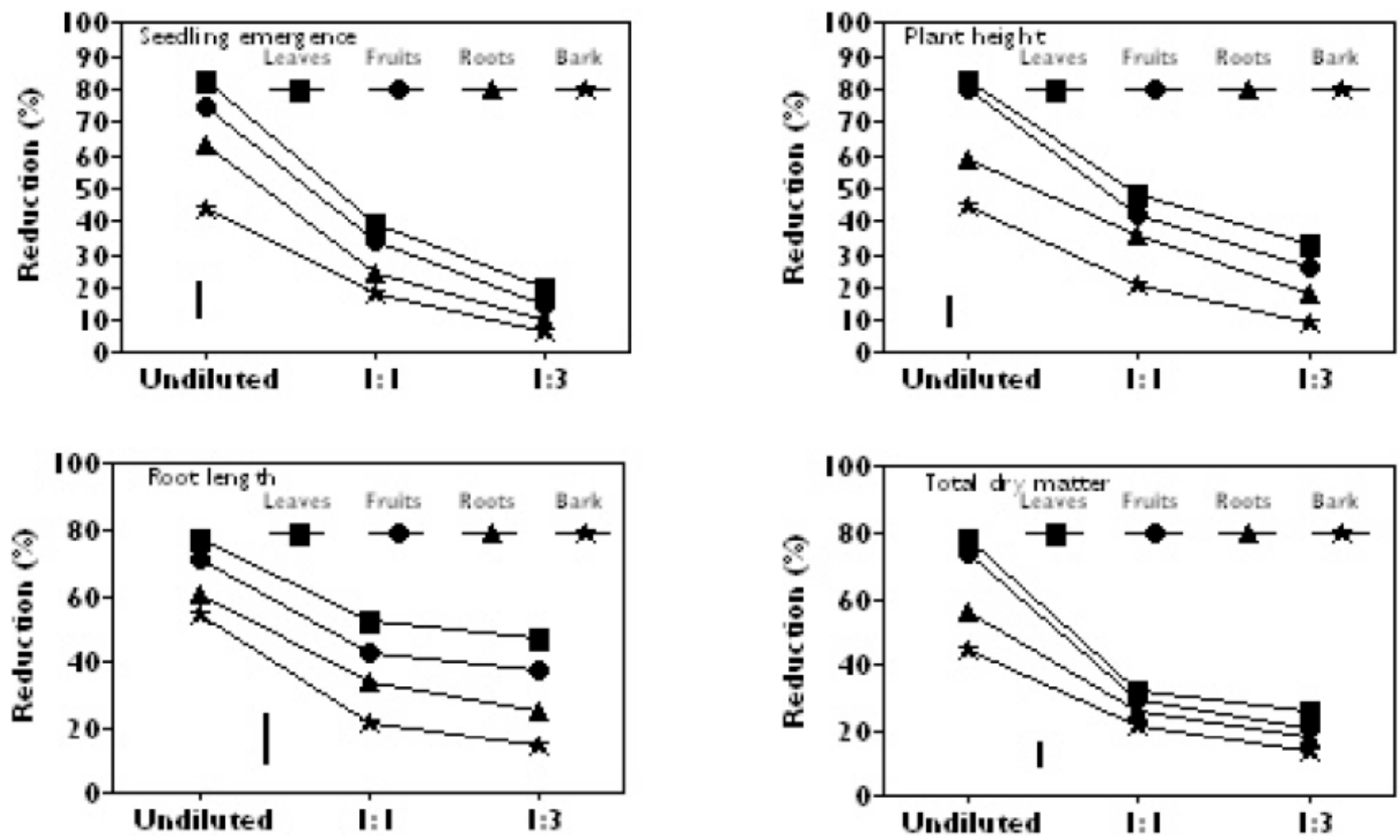

Fig. (2). Reductions in growth and development of wheat seedlings (expressed as proportion of the control) by the different dilutions of tree part extracts. The bar represents the least significant range at the 0.05 probability level according to the Duncan's Multiple Range Test.
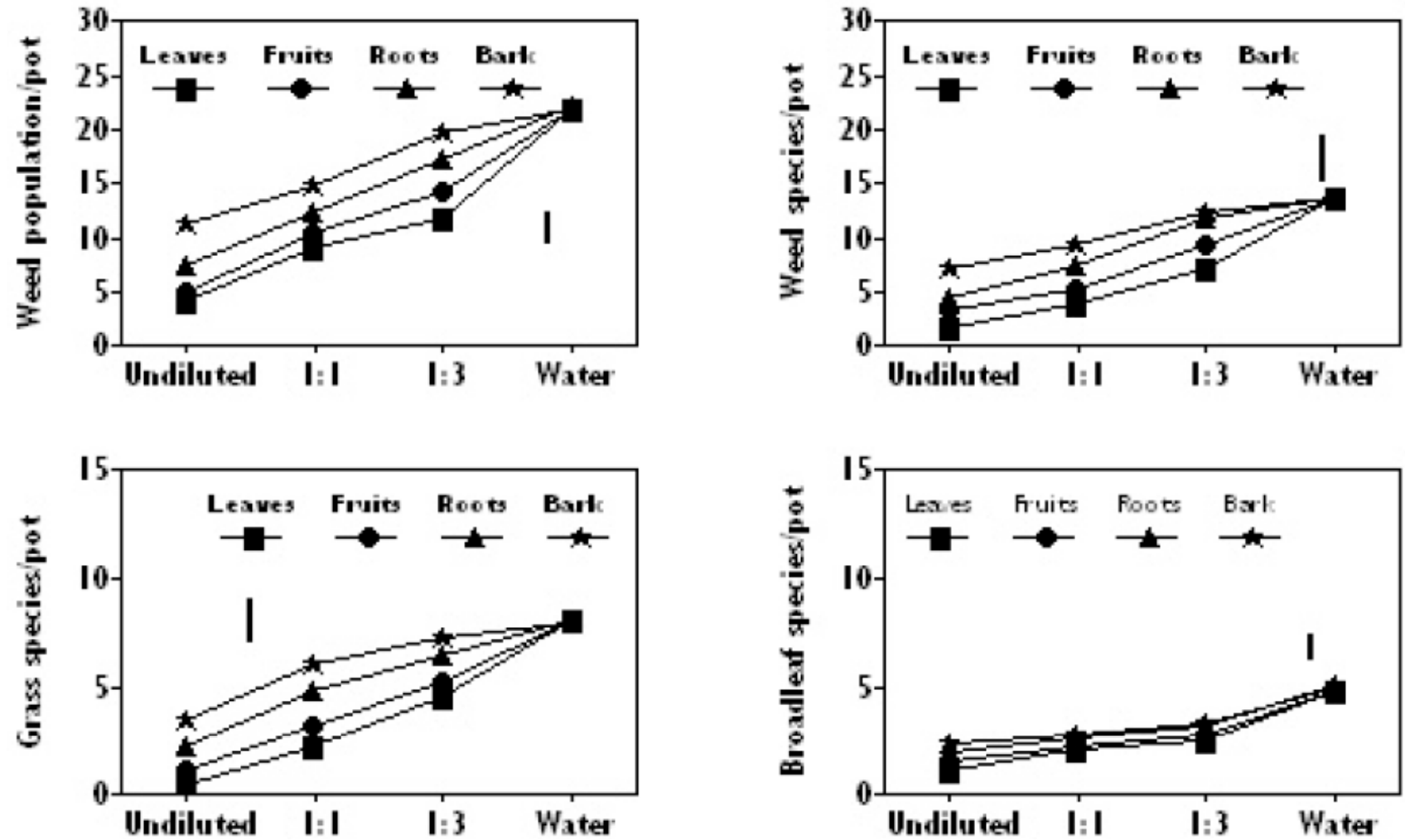

Fig. (3). The interactive effects of tree parts and their dilutions on weed population and species diversity. The bar represents the least significant range at the 0.05 probability level according to the Duncan's Multiple Range Test.

reduction in the occurrence of grass weed species was consistently higher than that for broadleaf weeds at each level of extract dilution.
Our previous studies [25] showed that the urea in the kraal manure did not reduce the emergence and growth of weed seedlings. Although the numbers of weed seeds in the 


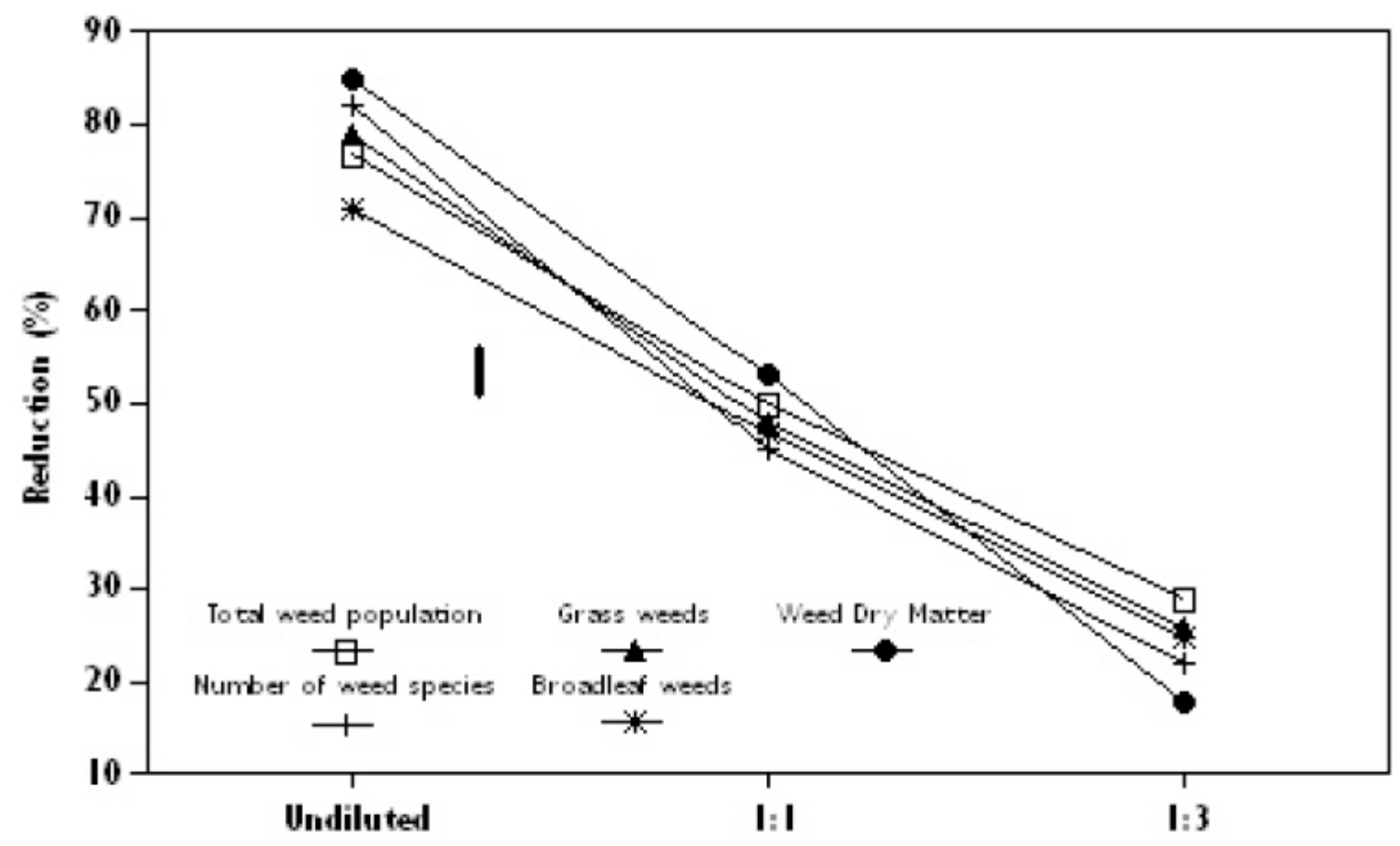

Fig. (4). Reductions in growth and development of weed seedling population and species diversity (expressed as proportion of the control) by the different dilutions of tree part extracts. The bar represents the least significant range at the 0.05 probability level according to the Duncan's Multiple Range Test.

Table 1. Numbers of Weed Species as Influenced by Aqueous Extracts from Pepper Tree Parts and their Dilution

\begin{tabular}{|c|c|c|c|c|c|c|c|c|c|c|}
\hline Species & Common Name & Family & \multicolumn{4}{|c|}{ Tree Part } & \multicolumn{4}{|c|}{ Dilution } \\
\hline \multicolumn{11}{|l|}{ Grass Weeds } \\
\hline Eleusine coracana (L.) Gaertn & Goose grass & Poacea (A) & $\mathrm{np}$ & $\mathrm{np}$ & 1 & 2 & np & 1 & 1 & 3 \\
\hline Cynodon dactylon (L.) Pers. & Common couch grass & Poaceae (P) & $\mathrm{np}$ & $\mathrm{np}$ & 1 & 3 & 1 & 1 & 2 & 4 \\
\hline Dactyloctenium australe & Sweet smother grass & Poaceae (A) & 1 & 1 & 3 & 1 & $\mathrm{np}$ & 1 & 3 & 5 \\
\hline Eragrostis lehmanniana & Lehmann's love grass & Poaceae (A) & $\mathrm{np}$ & 1 & 3 & 4 & $\mathrm{np}$ & 1 & 2 & 4 \\
\hline Sporobolus nitens & Curly leaved dropseed & Poaceae (A) & 1 & $\mathrm{np}$ & 1 & 1 & np & 2 & 3 & 5 \\
\hline \multicolumn{11}{|l|}{ Broadleaf Weeds } \\
\hline Amaranthus hybridus L. & Common pigweed & Amaranthaceae (A) & np & $\mathrm{np}$ & 1 & 3 & np & 1 & 2 & 3 \\
\hline Tagetes minuta $\mathrm{L}$. & Khaki weed & Asteraceae (A) & np & $\mathrm{np}$ & 3 & 5 & np & 1 & 2 & 3 \\
\hline
\end{tabular}

Letters in brackets describe the life form of the weed species in terms of annual (A) and perennial (P).

$\mathrm{L}=$ leaves; $\mathrm{F}=$ flowers; $\mathrm{R}=$ roots; $\mathrm{B}=$ bark; $\mathrm{np}=$ not present.

manure were not counted, the occurrence of significantly higher $(P<0.05)$ weed population and species in the control treatment (water) suggests that the extracts from parts of the pepper tree could have contained some biologically active compounds which had inhibitory effects on the emergence and development of both wheat and weed seedlings. These phytotoxic compounds need to be isolated and their behavior, activity and persistence well elucidated in future studies. This could help explain the observed bare patches under the canopies of the pepper trees.
Although the results of this study highlight potential where aspects of allelopathy may be exploited for practical weed control, the non-selective nature of the allelopathic chemical substances from the pepper tree extracts on both food crop and weeds implies that the method and time of utilization in the field must be properly established in order to avoid damage to crop seedlings. The use of phytotoxins by small-scale farmers may be cost-effective if they could be able to plant the trees with a food crop in intercropping. However, the control of weeds in a growing crop requires the use of selective herbicides which control the weeds while 
leaving the crop undamaged. This requirement may exclude the use of the tree in mixed or intercropping systems commonly practiced by small-scale farmers in South Africa and points to the need for extraction and formulation of the compounds. The process of extracting the phytotoxins from the tree may be complicated and/or expensive for individual farmers and may require the interest and involvement of large companies [31]. Furthermore, the nature of the phytotoxin present in the extracts, choice of formulation, mode of application and cost effectiveness of such an exploration needs to be established.

\section{CONCLUSIONS}

The study has shown that parts of the pepper tree may contain certain phytotoxins that inhibit the emergence and growth of wheat and weed seedlings. The potency of the phytotoxin in the different parts of the tree were in the order fruit=leaves $>$ roots $>$ bark. The inhibitory effects of the compounds on emergence and growth of wheat and weed seedlings was significantly reduced by diluting the original extracts with water. Emergence and diversity of grass weed species were more severely inhibited by the phytotoxins than in broad-leaved weeds. These results suggest that the pepper tree has potential in the development of natural herbicides for weed control in agriculture and that the fruits and leaves are the ones with the greatest potential. However, the nonselective nature of the phytotoxic effects of the phytotoxins on both crop and weeds presents a practical problem in terms of weed management and therefore, the appropriate economic way of exploiting this potential needs further investigation.

\section{ACKNOWLEDGEMENTS}

The authors are grateful to Mr. G.S. Gareseitse for assisting in the analysis of the soil and manure samples. We also acknowledge financial support, in form of a bursary, by the Faculty of Agriculture, Science and Technology to M.E.H.

\section{REFERENCES}

[1] Abdullahi AE. Weed survey in cotton (Gossypium hirstum L.) and sunflower (Helianthus annus L.) fields in the Pandamatenga plains of northeastern Botswana. S Afr J Plant Soil 2004; 21: 21-4.

[2] Rice EL. Allelopathy. Academic Press, New York 1974.

[3] Putnam AR. Allelopathy: a viable strategy for weed control? Proc Br Crop Prot Conf 1985; 2: 583-9.

[4] Reinhardt CF, Meissner R, Labuschagne N. Allelopathic interaction between chenopodium album L. and certain crop species. S Afr J Plant Soil 1994; 11: 45-9.

[5] Hong HN, Xuan TD, Eiji T, Hiroyuki T, Mitsuhiro M, Khahn TD. Screening for allelopathic potential of higher plants from Southeast Asia. Crop Prot 2003; 22: 829-36.

[6] Lin D, Sugitomo Y, Dong Y, Terao H, Matsuo M. Natural herbicidal potential of saururaceae (Houttuynia cordata Thumb) dried powders on paddy weeds in transplanted rice. Crop Prot 2006; 25: 1126-9.

[7] Liphadzi KB, Reinhardt CF. Using companion plants to assist Pinus patula establishment on former agricultural lands. S Afr J Bot 2006; 72: 403-8.
[8] Patrick ZA. Allelopathic mechanisms and their exploitation for biological control. Can J Plant Pathol 1986; 8: 225-8.

[9] Weston LA. Utilization of allelopathy for weed management in agro ecosystems. Agron J 1996; 88: 860-6.

[10] Singh HP, Batish DR, Kohli RK. Allelopathic interactions and phytotoxin: New possibilities for sustainable weed management. Crit Rev Plant Sci 2003; 22: 239-311.

[11] Batish DR, Arora K, Singh HP, Kohli RK. Potential utilization of dried powder of Tagetes minuta as a natural herbicide for managing rice weeds. Crop Prod 2007; 26: 566-71.

[12] Klein RR, Miller DA. Allelopathy and its role in agriculture. Commun Soil Sci Plant Anal 1980; 11: 43-56.

[13] Heap I. International survey of herbicide resistance weeds. Available online at URL:www.weedscience.com. 2006 (Accessed on 24 June 2007).

[14] Leather GR. Sunflower (Helianthus annuus) are allelopathic to weeds. Weed Sci 1983; 31: 37-42.

[15] Cáldiz DO, Fernandez LV. Allelopathy as a possible strategy for weed control in agriculture and forestry systems. In: Macias FA, Galindo JCG, Molinillo JMG, Cutler H, Eds. Recent Advances in Allelopathy. A Science for the Future. Servicio de publicacaciones, Universida de Cádiz, Cádiz 1999; Vol. 1: pp. 451-62.

[16] Hoffman GR, Hazlett DL. Effects of aqueous Artemesia extracts and volatile substances on germination of selected species. J Range Man 1977; 30: 134-7.

[17] Meissner R, Nel PC, Beyers EA. Allelopathic influence of Tagetesand Bidens- infested soils on seedling growth of certain crop species. S Afr J Plant Soil 1986; 3: 176-80.

[18] Katz DA, Sneh B, Friedman J. The allelopathic potential of Coridothrymus capitatus L. (Labiatae). Preliminary studies on the role of the shrub in the inhibition of annuals germination and/or to promote allelopathically active actinomycetes. Plant Soil 1987; 98: 53-66.

[19] Bond W, Grundy AC. Non-chemical weed management in organic farming systems. Weed Res 2001; 41: 383-405.

[20] Nel JL, Richardson DM, Rouget M, et al. A proposed classification of invasive alien plant species in South Africa: towards prioritizing species and areas for management action. S Afr J Sci 2004; 100: 53-64.

[21] Dikshit A, Naqvi AA, Husain A. Schinus molle: a new source of natural fungitoxicant. Appl Environ Microbiol 1986; 51: 1085-8.

[22] Mishra AK, Dubey NK. Evaluation of some essential oils for their toxicity against fungi causing deterioration of stored food commodities. Appl Environ Microbiol 1994; 60: 1101-5.

[23] Lannacone JO, Lamas G. Toxicological effects of extracts of Peruvian peppertree (Schinus molle) and lantana (Lanatan camara) on Chryoperia externa (Neuroptera: Chrysopidae), Trichogramma pintoi (Hymenoptera: Trichogrammatidae) and Copidosoma koehleri (Hymenoptera: Encyrtidae) in Peru. Agric Técnica 2003; 63: 347-60.

[24] Soil Classification Working Group. Soil Classification. A Taxonomic System for South Africa; Memoirs on the Agricultural Natural Resources of South Africa No. 15, Dept. Agric. Dev., Pretoria 1991.

[25] Materechera SA, Modiakgotla LN. Cattle manure increases soil weed population and species diversity in a semi-arid environment. S Afr J Plant Soil 2006; 23: 21-8.

[26] Botha C. Common Weeds of Crops and Gardens in Southern Africa. ARC-Grain Crops Institute, Potchefstroom 2001.

[27] Henderson M, Anderson JG. Common Weeds in South Africa. Botanical Survey, Memoir No. 37. Botanical Research Institute, Pretoria 1966.

[28] SAS INSTITUTE INC. SAS/STAT Users Guide. Version 6. SAS Inst., Cary, NY 1991; Vol 2.

[29] Snedecor GW, Cochran WG. Statistical Methods. $7^{\text {th }}$ ed. Iowa State Univ. Press, Ames, Iowa 1980.

[30] Acocks JPH. Veld Types of South Africa, $3^{\text {rd }}$ ed. Memoirs of the Botanical Survey of South Africa, No. 57. Pretoria 1988.

[31] SYNGENTA. WWW.SYNGENTA.COM; 2005. 